\title{
El presente y el futuro de la especialidad
}

\section{Pedro Manonelles Marqueta}

En muy poco tiempo se ha producido un cúmulo de circunstancias que nos han hecho abandonar nuestro trabajo cotidiano para tener que reflexionar sobre lo que somos. Somos especialistas en medicina de la educación física y el deporte, y trabajamos en los amplios contenidos que tiene nuestra especialidad. Parece obvio. Lo es para nosotros pero, por lo que hemos podido apreciar, no resulta evidente para otros estamentos, al menos, para algunos.

A finales del año pasado se aprobó la Ley de protección de la salud y de lucha contra el dopaje en el deporte. La medicina del deporte puede estar satisfecha de sus contenidos y de la responsabilidad de la Administración, concretamente del Consejo Superior de Deportes, porque, a través de la intermediación de la Organización Médica Colegial, se admitieron claros conceptos relacionados con la salud de los deportistas. A nadie se le ha escapado que la aplicación de esta Ley necesita la colaboración y el trabajo de un importante número de especialistas en medicina del deporte.

Lamentablemente, también a finales del año pasado se planteó un proyecto de Real Decreto "por el que se determinan y clasifican las especialidades en Ciencias de Salud y se desarrollan determinados aspectos del sistema de formación sanitaria especializada" que condenaba a nuestra especialidad a la desaparición.

Tras las primeras gestiones efectuadas con el Ministerio de Sanidad, autor del mencionado borrador, se ha suspendido inicialmente esta propuesta de supresión, aunque no será definitiva hasta que se acepte la propuesta de adecuación de formación de nuestra especialidad al sistema hospitalario. Resulta obvio decir que se está trabajando intensamente en ello. 
Pero todo este cúmulo de incidentes inesperados ha servido para algo más que para conmocionar al colectivo de profesionales que nos vemos afectados.

Hay dos temas principales que subyacen en la mente de todos nosotros: en orden cronológico, el primero es la representación de nuestra especialidad, y el segundo, el papel que ocupa y que debe ocupar nuestra especialidad en la sociedad.

Una vez que se plantearon la ley de salud y dopaje, por abreviar, y la amenaza de supresión de la especialidad, desde la Federación Española de Medicina del Deporte se tuvo muy claro que, si se quería lograr algún avance y aceptación de los objetivos de la medicina del deporte, se tenía que presentar una propuesta unánime ante los organismos competentes. Inmediatamente se contactó con la Federación Española de Asociaciones de Especialistas en Medicina de la Educación Física y el Deporte (FEDAMEFYDE), y fuimos capaces de plantear una propuesta conjunta en ambos casos. Sin duda, éste es uno de los motivos principales por los que hemos alcanzado logros enormes para el ejercicio de nuestra profesión. Pero estamos convencidos de que algunas de nuestras reclamaciones no han podido ser aceptadas probablemente por la atomización de la medicina del deporte. Si se analiza el espectro de la medicina del deporte, especialidad joven y con pocos profesionales, se observará la diversidad de asociaciones existentes. El número de especialistas no parece justificar semejante disgregación. Esto nos debería hacer reflexionar profundamente. Todos tenemos claro el sentido de nuestra especialidad, y también tenemos claro que somos equiparables al resto de especialidades médicas, pero las especialidades médicas tradicionales y establecidas sólo tienen, a excepción de la medicina general, una sociedad científica...

El segundo aspecto es la reflexión sobre los ámbitos de trabajo de nuestra especialidad. Hemos pasado de ocupar un lugar testimonial en el contexto deportivo, a constituir un elemento primordial en la práctica de deporte desarrollado. Es evidente que esto obedece a la evolución y al progreso de la sociedad en la que vivimos, en la que más de una cuarta parte de la población española actual está implicada en las diversas prácticas de actividad fisicodeportiva, desde la profesional o de alto rendimiento, hasta la recreacional, pasando por todas las demás, 
como ejercicio terapéutico, actividades de mantenimiento para mejora de la salud y preservación de la independencia del anciano, actividades deportivas para discapacitados, deporte escolar y de progresión, etc.

Sin pretender realizar un análisis exhaustivo de los ámbitos de actuación de nuestra especialidad en el momento presente, se deben de recordar algunos de ellos, como:

- La realización de reconocimientos medicodeportivos preparticipación para la certificación de aptitud para la práctica deportiva, que es una demanda secular de nuestra especialidad y que se encuentra en una fase de desarrollo inmediato.

- La promoción de la salud, mediante la prescripción de ejercicio físico y/o deporte, que entre muchas otras ventajas permite la reducción del gasto farmacéutico. El ejercicio físico ocupa un lugar destacado entre las diversas estrategias de tratamiento de diversas enfermedades, como la obesidad y las enfermedades cardiovasculares, entre muchas otras.

- La prevención de patologías mediante la práctica de ejercicio físico.

- La evaluación, diagnóstico y tratamiento de patologías derivadas del deporte.

- El soporte y el control científico del entrenamiento deportivo, especialmente en atletas en régimen de tecnificación o de rendimiento.

- La asistencia médica y urgente en acontecimientos deportivos, pendiente de desarrollo actual por parte de la Ley de Protección de la Salud y Lucha contra el Dopaje en el Deporte.

- El asesoramiento y gestión medicodeportiva en el establecimiento de normativas deportivas, instalaciones, control de instalaciones, organización médica de actividades deportivas, etc.

- La docencia e investigación en medicina de la educación física y el deporte.

- El trabajo relacionado con la lucha contra el dopaje. 
Sólo querría destacar que ante el aluvión de iniciativas o propuestas de utilización del ejercicio físico para mejora de la salud que ha surgido por parte de diversos colectivos de diversa procedencia, hay que recordar o incluso poner de manifiesto que la prescripción, aunque sea de ejercicio, es un acto exclusivamente médico, que debe ser acordado e impuesto por el facultativo, sin que se inmiscuyan otros profesionales ávidos de ocupar parcelas que, como sucede con la prescripción, no les corresponden. Pero el médico debe realizar el esfuerzo de luchar por esta prerrogativa, por los contenidos y responsabilidades de su trabajo, y no ceder a intereses injustificados y malsanos.

Pero además, la prescripción de ejercicio requiere un proceso laborioso que exige no sólo un diagnóstico, sino una valoración de la aptitud física del paciente. Este proceso debe ser realizado según los patrones de prescripción bien conocidos que, en muchas ocasiones, requieren valoración funcional en esfuerzo, previa a las recomendaciones de ejercicio.

Este procedimiento debe ser realizado por profesionales formados en prescripción de ejercicio como cardiólogos, neumólogos, rehabilitadores... y, por supuesto, por especialistas en medicina del deporte.

Los especialistas en medicina de la educación física y el deporte y sus dirigentes deben realizar un esfuerzo colectivo de reflexión sobre su presente para poder dibujar un futuro que, estamos convencidos, nos depara el asentamiento y consolidación de una especialidad necesaria y, en algunos aspectos, indispensable para nuestra sociedad. 